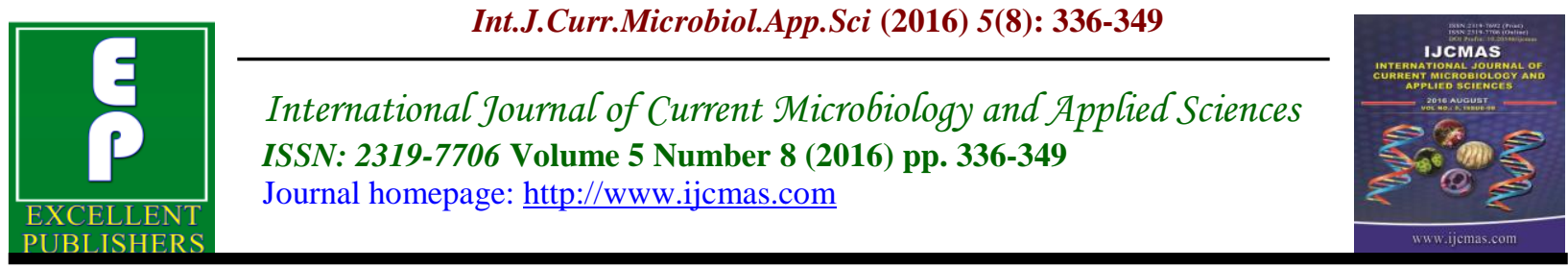

Original Research Article

http://dx.doi.org/10.20546/ijcmas.2016.508.036

\title{
Usage of Banana Pseudostem Waste for the Production of Potassic Biofertilizer using Cellulolytic Bacteria
}

\author{
R. Mahalakshmi* and M. Linnett Naveena \\ Department of Microbiology, Ethiraj College for Women, \\ Chennai -600 008, Tamil Nadu, India \\ *Corresponding author
}

Keywords

Cellulolytic bacteria, Banana, Pseudostem, Solid state fermentation, Potassium.

Article Info

Accepted:

17 July 2016

Available Online:

10 August 2016

\section{A B S T R A C T}

The present study aims to use banana pseudostem waste for the production of potassic biofertilizer using cellulolytic bacteria. Ten cellulolytic bacteria were isolated from soil samples collected from the College campus. After preliminary tests and biochemical tests, the cellulolytic bacteria were identified. The bacterial isolate which showed maximum cellulolytic activity (D8) was found to be Bacillus aerius by 16 s rRNA sequencing. Its 16 s rRNA sequence was submitted to Genbank and the accession number is KX530930.Appreciable amount of cellulolytic activity were shown by five different bacterial genera which were identified as Bacillus circulans (C3), Pseudomonas stutzeri (C4), Serratia rubidaea (C6),Bacillus subtilis (D1) and Bacillus pumilus (D2). These isolates were used alone and in consortium to degrade the banana pseudostem waste by solid state fermentation to obtain the fermented liquid. Analysis of the potassium content of the liquid by ICP-MS indicated that the potassium content is directly proportional to the cellulolytic activity of the bacteria. Tests done to check the effect of fermented liquid on plant growth revealed good increase in root length, shoot length, fresh weight, dry weight and chlorophyll content of fenugreek plants.

\section{Introduction}

India is an agriculture based country. Agriculture along with fisheries and forestry is one of the largest contributors of Gross Domestic Product (GDP). Proper management and disposal of agro waste is necessary to prevent various environmental issues.

Agro waste is defined as the waste which is produced from various agricultural activities. Accumulation of agro wastes may cause health, safety, environmental and aesthetic concern. (Lim and Matu, 2015) Agro wastes are rich in nutrients and can be used to improve soil fertility.

Cellulose is the major component of agro waste. It is an abundant natural polymer on earth. It is a linear polysaccharide of $\beta$-Dglucose residues with $\beta$-1, 4-glycosidic linkages. Cellulolytic bacteria are those bacteria that convert cellulose into soluble sugar. The complete degradation of cellulose is made by a cellulolytic enzyme system. It involves three enzyme systems. They are 
endoglucanases, exoglucanases and $\beta$-Dglucosidase. Endoglucanases act internally on the chain of cellulose cleaving $\beta$-linked bond liberating non reducing ends. Exoglucanases removes cellobiose from this non reducing end of cellulose chain. $\beta$-DGlucosidase splits cellobiose into glucose molecules.

Banana (Musa sp) is the second most important fruit crop in India. India leads the world in banana production with an annual output of about 14.2 million tonnes. The part of the plant which looks like a trunk is actually a false stem (pseudostem). It contains $50-60 \%$ of cellulose. According to the literature survey done, much attention was not paid on banana pseudostem as a source of potassium, although it contains 5.6-6.2\% of potassium (Saibaba et al., 2013).

The principle behind the present study is that cellulose degrading bacteria can be isolated from soil and can be allowed to degrade the cellulose in banana pseudostem waste by solid state fermentation. In this process, the potassium which is bound to cellulose fibres gets released and gets dissolved in the fermented liquid. The fermented pseudostem waste liquid contains high amount of potassium. This solution also contains cellulolytic bacteria. It can be used as liquid potassic biofertilizer. The potassium present in the liquid promotes plant growth and the cellulolytic bacteria will degrade other organic matter in soil and release various macronutrients and thereby promotes plant growth.

Using this simple and efficient method Banana pseudostem which is considered to be an agricultural waste can be routed back to enhance the agricultural productivity. There are many constraints in using potassium solubilizing bacteria (KSB) as potassic bioferilizers. Thus, Potassic biofertilizer produced using cellulolytic bacteria with banana pseudostem waste as substrate can be used as an alternative.

\section{Materials and Methods}

\section{Soil sample collection}

Soil samples were collected from two different places in the college campus and they were labelled as soil sample 1 and soil sample 2 respectively. The soil samples were collected in a sterile petri plate and were aseptically brought to the lab.

\section{Isolation of cellulolytic bacteria}

\section{Serial dilution and spread plating}

$1 \mathrm{~g}$ of soil sample was taken and it was serially diluted using decimal dilution technique. $0.1 \mathrm{ml}$ from $10^{-7,} 10^{-8}$ and $10^{-9}$ dilutions were inoculated onto sterile nutrient agar plates by spread plating. The plates were incubated at $37^{\circ} \mathrm{c}$ for 24 hours. The colonies with varied morphology were selected and were streaked on to separate nutrient agar plates. All the plates were incubated at $37^{\circ} \mathrm{c}$ for 24 hours.

\section{Congo Red Assay}

Congo red assay was carried out according to the method described by Kaur and Arora, (2012).This method serves as primary screening to isolate cellulolytic bacteria. The isolates that show positive results for primary screening were selected and were taken to secondary screening. Negative isolates were discarded.

\section{Secondary Screening}

CMCase assay serves as secondary screening for the determination of cellulolytic activity.It was done according to the method described by Khan et al., 2011. 
One unit of CMCase is expressed as micromoles of glucose liberated per $\mathrm{ml}$ enzyme used per minute.

\section{Identification of cellulolytic bacteria}

\section{Identification of isolates}

The isolates were subjected to preliminary tests such as gram staining, motility test, catalase test, oxidase test and endospore staining. Biochemical tests such as IMViC TEST, TSI test Urease test, Nitrate test, Carbohydrate fermentation test, PDA test, Arabinose test and Starch hydrolysis test were done. Growth of the isolates in $6.5 \%$ Nacl, basal media, differential media and selective media were checked. Based on the results of these tests the organisms were identified using Bergey's Manual of Determinative Bacteriology and Bergey's Manual of Systematic Bacteriology.

\section{Identification of the best cellulolytic bacteria by $16 \mathrm{~s}$ rRNA sequencing}

The identification of the isolate with maximum cellulolytic activity was confirmed by $16 \mathrm{~s}$ rRNA sequencing. The protocol provided is as follows:

\section{DNA Extraction}

Bacterial Genomic DNA was isolated using the InstaGeneTM Matrix Genomic DNA isolation kit - As per the kit instruction below procedure followed. An isolated bacterial colony was picked and suspended in $1 \mathrm{ml}$ of sterile water in a microfuge tube. It was centrifuged for 1 minute at 10,000 $12,000 \mathrm{rpm}$ to remove the supernatant. 200 $\mu \mathrm{l}$ of Insta Gene matrix was added to the pellet and was incubated at $56{ }^{\circ} \mathrm{C}$ for 15 minutes. It was vortexed at high speed for 10 seconds and the tube was placed in a 100 ${ }^{\circ} \mathrm{C}$ in heat block or boiling water bath for 8 minutes. Finally, the contents were vortexed at high speed for 10 seconds and were spinned at 10,000-12,000 rpm for 2 minutes. $20 \mu \mathrm{l}$ of the supernatant was used per $50 \mu \mathrm{l}$ PCR reaction.

\section{PCR Protocol}

Using 16s rRNA Universal primers, gene fragment was amplified using MJ Research Peltier Thermal Cycler. Universal primer details were shown in table $1.1 \mu \mathrm{L}$ of template DNA was added in $20 \mu \mathrm{L}$ of PCR reaction solution. 27F/1492R primers were used for bacteria and then PCR reaction was performed with below conditions:

Initial Denaturation $94^{\circ} \mathrm{C}$ for $2 \mathrm{~min}$ and then 35 amplification cycles at $94^{\circ} \mathrm{C}$ for $45 \mathrm{sec}$, $55^{\circ} \mathrm{C}$ for $60 \mathrm{sec}$, and $72^{\circ} \mathrm{C}$ for $60 \mathrm{sec}$. Final Extension at $72^{\circ} \mathrm{C}$ for $10 \mathrm{~min}$. DNA fragments are amplified about1,400bp in the case of bacteria. A positive control (E.coli genomic DNA) and a negative control were included in the PCR.

\section{Purification of PCR products}

Unincorporated PCR primers and dNTPs were removed from PCR products by using Montage PCR Clean upkit (Millipore).The PCR product was sequenced using the 518F/800R primers. Sequencing reactions were performed using a ABI PRISM ${ }^{\circledR}$ BigDyeTM Terminator Cycle Sequencing Kits with AmpliTaq ${ }^{\circledR}$ DNA polymerase (FS enzyme) (Applied Biosystems).

\section{Sequencing protocol}

Single-pass sequencing was performed on each template using below 16s rRNA universal primers. The fluorescent-labelled fragments were purified from the unincorporated terminators with an ethanol precipitation protocol. The samples were 
resuspended in distilled water and subjected to electrophoresis in an ABI 3730xl sequencer (Applied Biosystems). Sequencing primer details were shown in table 2.

\section{Bioinformatics protocol}

The 16s $\mathrm{r}$ RNA sequence was blast using NCBI blast similarity search tool. The phylogeny analysis of our sequence with the closely related sequence of blast results was performed followed by multiple sequence alignment.

The program MUSCLE 3.7 was used for multiple alignments of sequences (Edgar 2004). The resulting aligned sequences were cured using the program Gblocks 0.91b. This Gblocks eliminates poorly aligned positions and divergent regions (removes alignment noise) (Talavera and Castresana2007).Finally, the program PhyML 3.0 aLRT was used for phylogeny analysis and HKY85 as Substitution model.

PhyML was shown to be at least as accurate as other existing phylogeny programs using simulated data, while being one order of magnitude faster. The program Tree Dyn 198.3 was used for tree rendering (Dereeper et al., 2008)

Usage of Cellulolytic Bacteria to Degrade Banana Pseudostem Waste (Dabhi et al., 2014)

Preparation of Banana Pseudostem Waste (Dabhi et al., 2014)

Banana pseudostem waste was dried in sunlight. It was cut into $2 \mathrm{~cm}$ pieces.

\section{Inoculum Selection and Preparation} (Dabhi et al., 2014)

Best 5 isolates of cellulolytic bacteria (C3, C4, C6, D2 and D8) were selected among the 10 isolated cellulolytic bacteria on the basis of primary screening and secondary screening. A loop full of broth culture of the 5 cellulolytic bacterial isolates were separately inoculated into CMC broth tubes (5ml).

A consortium (a loop full of the best 5 cellulolytic bacteria) was also inoculated separately into CMC broth tubes $(5 \mathrm{ml})$.All the tubes were incubated at $37^{\circ} \mathrm{c}$ for 48 hours. After 48 hours, the culture in these tubes serves as inoculum.

\section{Solid State Fermentation}

(Dabhi et al., 2014), (Lim and Matu, 2015) $6.25 \mathrm{~g}$ of banana pseudostem waste and $18.75 \mathrm{ml}$ of distilled water was added to 250 $\mathrm{ml}$ conical flask. It was cotton plugged and was sterilized by autoclaving. After cooling, $5 \mathrm{ml}$ of inoculum was added to it and was incubated at $37^{\circ} \mathrm{c}$ for 40 days.

\section{Recovery of Fermented Banana Pseudostem Waste (Lim and Matu, 2015)}

The fermented banana pseudostem waste was recovered by filtering the fermented waste using fabricated filters.

Biofertilizer Analysis (Lim and Matu, 2015)

\section{pH Analysis}

The purpose of the $\mathrm{pH}$ analysis is to find out whether the $\mathrm{pH}$ of the biofertilizer can support plant growth.pH analysis was done using $\mathrm{pH}$ meter.

\section{Potassium Content Analysis}

The Potassium content of Fermented Banana Pseudostem Waste Liquid (FBPWL) samples were analysed using Inductively Coupled Plasma Mass Spectrophotometer (ICP-MS). 


\section{Efficiency of FBPWL on Fenugreek Plants}

The efficiency of FBPWL as liquid potassic biofertilizer was checked by pot trials using fenugreek plants.

Seed Treatment (Lim and Matu, 2015)

Fenugreek seeds were soaked in FBPWL for 24 hours and they were sown in pots. Seeds soaked in FBPWL-Consortium were sown in pots labelled CONSORTIUM. Similarly seeds soaked in FBPWL-D8, FBPWL-D2, FBPWL-C4, FBPWL-C6 and FBPWL-C3 were sown in pots labelled D8, D2, C4, C6 and $\mathrm{C} 3$ respectively. Duplicates were made. Untreated seeds were sown in control pot. All the pots were kept in open space under sunlight. The plants were watered daily. Their growth was monitored for 3 weeks.

Plant Growth Analysis (Kapoor and Pande, 2015)

The root length, shoot length, fresh weight and dry weight of the plants were measured. The chlorophyll content of the leaves were measured.

\section{Results and Discussion}

\section{Isolation of cellulolytic bacteria}

\section{Spread plating}

From soil sample 1, thirteen colonies with varied morphology were isolated. They were named as $\mathrm{C} 1, \mathrm{C} 2, \mathrm{C} 3, \mathrm{C} 4, \mathrm{C} 5, \mathrm{C} 6, \mathrm{C} 7, \mathrm{C} 8$, $\mathrm{C} 9, \mathrm{C} 10, \mathrm{C} 11, \mathrm{C} 12$ and $\mathrm{C} 13$ respectively. From soil sample 2, eight colonies with varied morphology were isolated. They were named as D1, D2, D3, D4, D5, D6, D7 and D8.

\section{Congo Red Assay}

In Congo red assay with $\mathrm{CMC}$ agar, isolates $\mathrm{C} 3, \mathrm{C} 4, \mathrm{C} 6, \mathrm{C} 9, \mathrm{C} 10, \mathrm{C} 11, \mathrm{C} 12, \mathrm{D} 1, \mathrm{D} 2$ and
D8 formed the zone of hydrolysis. Thus by Congo red assay with CMC agar, isolates C3, C4, C6, C9, C10, C11, C12, D1, D2 and D8 were identified as cellulolytic bacteria. The isolates that did not form the zone of hydrolysis were discarded. (i.e. Isolates $\mathrm{C} 1$, C2, C7, C8, C11, C13, D3, D4, D5, D6 and D7 were discarded). Its results were shown in table 3 and chart 1.The plate showing the zone of hydrolysis was shown in figure 2 .

\section{CMCase Assay}

Among the isolates tested, D8 showed the highest enzyme concentration. The isolates in the descending order of CMCase production is as follows: $\mathrm{D} 8, \mathrm{D} 2, \mathrm{C} 4, \mathrm{C} 6$, C3, D1, C10, C9, C11 and C12.Its results were shown in table 3 and Chart 2.

\section{Identification}

On the basis of the results of preliminary tests and biochemical tests, the identification of isolates was made with reference to the Bergey's Manual of Determinative Bacteriology and Bergey's Manual of Systematic Bacteriology. C3 was identified as Bacillus circulans, $\mathrm{C} 4$ as Pseudomonas stutzeri, C6 as Serratia rubidaea, C9 as Bacillus simplex, $\mathrm{C} 10$ as Bacillus coagulans, $\mathrm{C} 11$ as Pseudomonas fragi, $\mathrm{C} 12$ as Bacillus megaterium, D1 as Bacillus subtilis, D2 as Bacillus pumilus and D8 as Bacillus aerius. The colony morphology of the isolates were shown in figure 1 .

Confirmation of the Identification of the Best Cellulolytic Bacteria By 16s Rrna Sequencing

Among the 10 isolates, D8 was found to have the highest cellulolytic activity. By $16 \mathrm{~s}$ rRNA sequencing D8 was identified as Bacillus aerius. Its phylogenetic tree was shown in figure 4.The 16s rRNA sequence of Bacillus aerius D8 was submitted to 
Genbank and the accession number is KX530930.

\section{Solid State Fermentation of Banana Pseudostem Waste with Cellulolytic Bacteria}

Softening and water release was seen in the inoculated flasks. Water release occurred due to hydrolysis of cellulose in the banana pseudostem waste. Softening and water release was not seen in the control flask (control). After 40 days, $30-35 \mathrm{ml}$ of fermented liquid was recovered from each inoculated flask. The control yielded $7 \mathrm{ml}$ of liquid.

\section{Bio Fertilizer Analysis}

The results of $\mathrm{pH}$ analysis and potassium content analysis of FBPWL by Inductively coupled Plasma Mass Spectrophotometer were shown in table 4 and chart 3.

\section{Pot Analysis}

When compared to the FBPWL treated plants the germination and growth of the untreated plants were delayed. The results of plant growth analysis were shown in table 5 and chart 4 . The root length and shoot length of the plants were shown in figure 3 .

\section{Selection of agrowaste}

To produce a biofertilizer from agrowaste using microbial action, three factors has to be considered. They are as follows:1.Type of bio fertilizer to be produced, 2.Type of agrowaste and 3. Type of culture. On the basis of the type of biofertilizer need to be produced, the agrowaste has to be selected and on the basis of the chemical and physical properties of the agrowaste the culture has to be selected. The objective of the present study is to produce potassic bio fertilizer from agro waste. Banana pseudostem waste is the most abundant agro waste in India. It is rich in potassium ( $\mathrm{Li}$ et al., 2010; Saibaba et al., 2013 and Kinekar, 2010). So it has been chosen for the study. Cellulose is the major component of banana pseudostem waste so cellulolytic bacteria is used to degrade the cellulose in banana pseudostem and thereby to release the potassium bound to it. Moreover cellulolytic bacteria are one of the common soil bacteria.

\section{Isolation of Cellulolytic Bacteria from Soil}

The present study, proves for the first instance, that Bacillus circulans, Serratia rubidaea, Bacillus simplex, Pseudomonas fragi and Bacillu aerius also possess cellulolytic activity. The isolated cellulolytic bacteria were the most common cellulolytic bacteria present in the soil. Bacillus aerius is an organism that has been discovered in 2006 by Shivaji et al., 2006. It has been isolated from cryogenic tubes used for collecting air samples from high altitudes.

Till date it has not been isolated from any other source. In this study, it has been isolated from soil sample and was found to have the highest cellulolytic activity among the isolates.

\section{Congo Red Assay and CMCase Assay}

The results of Congo red assay matches with the results of CMCase assay. Isolate D8 (Bacillus aerius) was found to have the maximum cellulolytic activity in Congo red assay. Its zone diameter was $3.2 \mathrm{~cm}$. In CMCase assay, isolateD8 (Bacillus aerius) showed maximum cellulase production of $0.43 \mathrm{U} / \mathrm{ml} / \mathrm{min}$.

Solid State
$\begin{aligned} & \text { Fermentation } \\ & \text { Pseudostem } \\ & \text { Bacteria }\end{aligned}$


Softening and water release was seen in the inoculated flasks. Water release occurred due to hydrolysis of cellulose in the banana pseudostem waste.

\section{Potassium Content of FBPWL}

On analysing the results of potassium content of Fermented Banana Pseudostem Waste Liquid (FBPWL), it was found that as the cellulolytic activity increases, the potassium content in the fermented liquid also increases. Cellulolytic activity is proportional to the potassium content in the fermented liquid.

Isolate D8 has the highest cellulolytic activity among the isolates and its respective FBPWL has the highest potassium content of $10470 \mathrm{ppm}$. The potassium content of FBPWL of consortium (11400 ppm) is greater than that of FBPWL of D8 (10470 ppm).

This indicates that the organisms D8 (Bacillus aerius), D2 (Bacillus pumilus), C4 (Pseudomonas stutzeri), C6 (Serratia rubidaea) and C3 (Bacillus circulans) can coexist. As combined effect of the cellulolytic activity of these organisms is more, the potassium content in FBPWLConsortium is more. When the potassium content of the liquid obtained from control was analysed, it was found that it contains $1300 \mathrm{ppm}$ of potassium. The potassium release in the control would have occurred due to diffusion. As the potassium in banana pseudostem waste is bound to the cellulosic fibres (Li et al., 2010), it is difficult to remove the potassium from it without loosening the cellulosic fibres. Thus cellulolytic activity has loosened the cellulose fibres in banana pseudostem waste and have resulted in release of high amount of potassium in fermented liquid.

\section{FBPWL As biofertilizer}

The fermented banana pseudostem waste contains potassium and cellulolytic bacteria. Potassium will improve plant growth and cellulolytic bacteria being a normal flora of the soil will help in degrading the cellulosic wastes in the soil and release the bound nutrients and there by increases the growth of plants. The isolated cellulolytic bacteria were the most common cellulolytic bacteria present in the soil.

On analysing the results of plant growth studies with Fermented Banana Pseudostem Waste Liquid, it was found that as the potassium content in FBPWL increases, the shoot length, root length, fresh weight, dry sweight and chlorophyll content also increases. Plants grown with FBPWLConsortium showed the highest shoot length, root length, fresh weight, dry weight and chlorophyll content among the plants under study.

Table.1 Universal Primer Details

\begin{tabular}{|l|l|l|}
\hline Primer Name & Sequence Details & Number of Base \\
\hline $27 \mathrm{~F}$ & AGAGTTTGATCMTGGCTCAG & 20 \\
\hline $1492 \mathrm{R}$ & TACGGYTACCTTGTTACGACTT & 22 \\
\hline
\end{tabular}


Table.2 Sequencing Primer Details:

\begin{tabular}{|l|l|l|}
\hline Primer Name & Sequence Details & Number of Base \\
\hline $\mathbf{7 8 5 F}$ & GGATTAGATACCCTGGTA & 18 \\
\hline $\mathbf{9 0 7 R}$ & CCGTCAATTCMTTTRAGTTT & 20 \\
\hline
\end{tabular}

Table.3 Results of Congo Red Assay and CMCase assay

\begin{tabular}{|c|c|c|c|c|c|c|c|c|c|c|}
\hline Isolate & C3 & C4 & C6 & C9 & C10 & C11 & C12 & D1 & D2 & D8 \\
\hline Zone Diameter $(\mathbf{C m})$ & 2.5 & 2.8 & 2.7 & 0.9 & 1 & 0.9 & 0.7 & 2 & 3 & 3.2 \\
\hline $\begin{array}{c}\text { Enzyme Concentration } \\
(\mathbf{U} / \mathbf{m l} / \mathbf{m i n})\end{array}$ & 0.17 & 0.23 & 0.17 & 0.10 & 0.14 & 0.04 & 0.03 & 0.16 & 0.31 & 0.43 \\
\hline
\end{tabular}

Table.4 Results of Biofertilizer analysis

\begin{tabular}{|l|l|l|}
\hline Sample & $\mathbf{p H}$ & Potassium Content (ppm) \\
\hline FBPWL-CONSORTIUM & 7.02 & $\mathbf{1 1 4 0 0}$ \\
\hline FBPWL-D8 & 7.18 & 10470 \\
\hline FBPWL-D2 & 7.23 & 10025 \\
\hline FBPWL-C4 & 7.30 & 7350 \\
\hline FBPWL-C6 & 7.31 & 6500 \\
\hline FBPWL-C3 & 7.45 & 6300 \\
\hline FBPWL-CONTROL & 8.45 & 1300 \\
\hline
\end{tabular}

Table.5 Results of Plant growth analysis

\begin{tabular}{|l|l|l|l|l|l|}
\hline PLANT & $\begin{array}{l}\text { SHOOT } \\
\text { LENGTH } \\
(\mathbf{c m})\end{array}$ & $\begin{array}{l}\text { ROOT } \\
\text { LENGTH } \\
(\mathbf{c m})\end{array}$ & $\begin{array}{l}\text { FRESH } \\
\text { WEIGHT } \\
(\mathbf{g})\end{array}$ & $\begin{array}{l}\text { DRY } \\
\text { WEIGHT } \\
(\mathbf{g})\end{array}$ & $\begin{array}{l}\text { CHLOROPHYLL } \\
\text { CONTENT (mg/g) }\end{array}$ \\
\hline $\begin{array}{l}\text { PLANT-FBPWL- } \\
\text { CONSORTIUM }\end{array}$ & 16.9 & 8.3 & 15.2 & 1.24 & $\mathbf{3 . 6 6 9}$ \\
\hline PLANT-FBPWL-D8 & 16.0 & 8.0 & 13.9 & 1.02 & $\mathbf{3 . 4 3 8}$ \\
\hline PLANT-FBPWL-D2 & 15.5 & 7.2 & 12.7 & 0.98 & 2.995 \\
\hline PLANT-FBPWL-C4 & 14 & 6.9 & 10.9 & 0.94 & 2.862 \\
\hline PLANT-FBPWL-C6 & 13.7 & 6.7 & 10.6 & 0.96 & 2.862 \\
\hline PLANT-FBPWL-C3 & 11.2 & 5.0 & 9.7 & 0.90 & 2.036 \\
\hline $\begin{array}{l}\text { PLANT-FBPWL- } \\
\text { CONTROL }\end{array}$ & 9.0 & 4.2 & 7.8 & 0.62 & 1.697 \\
\hline
\end{tabular}


Chart.1 Results of Congo Red Assay

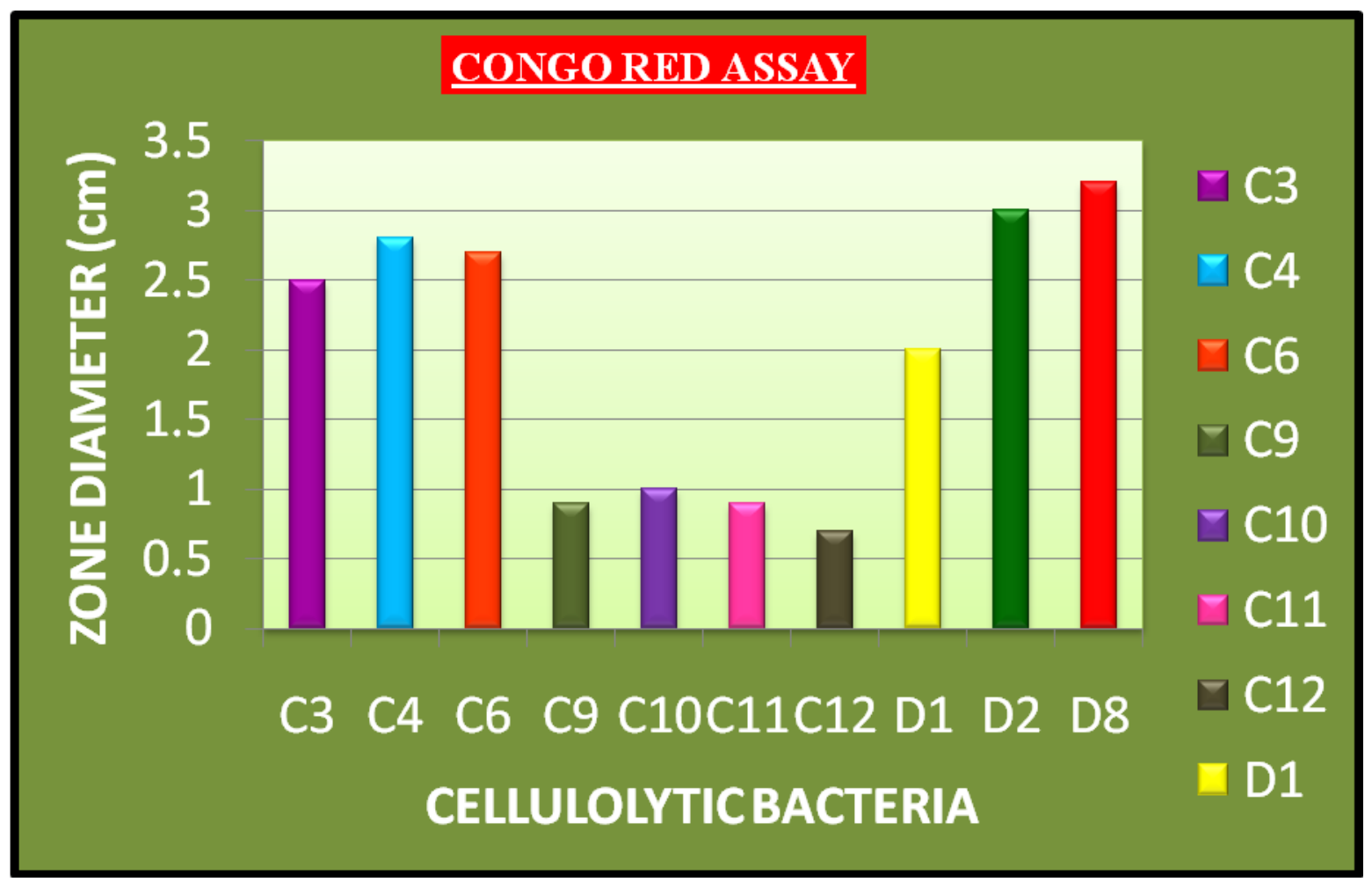

Chart.2 Results of CMCase Assay

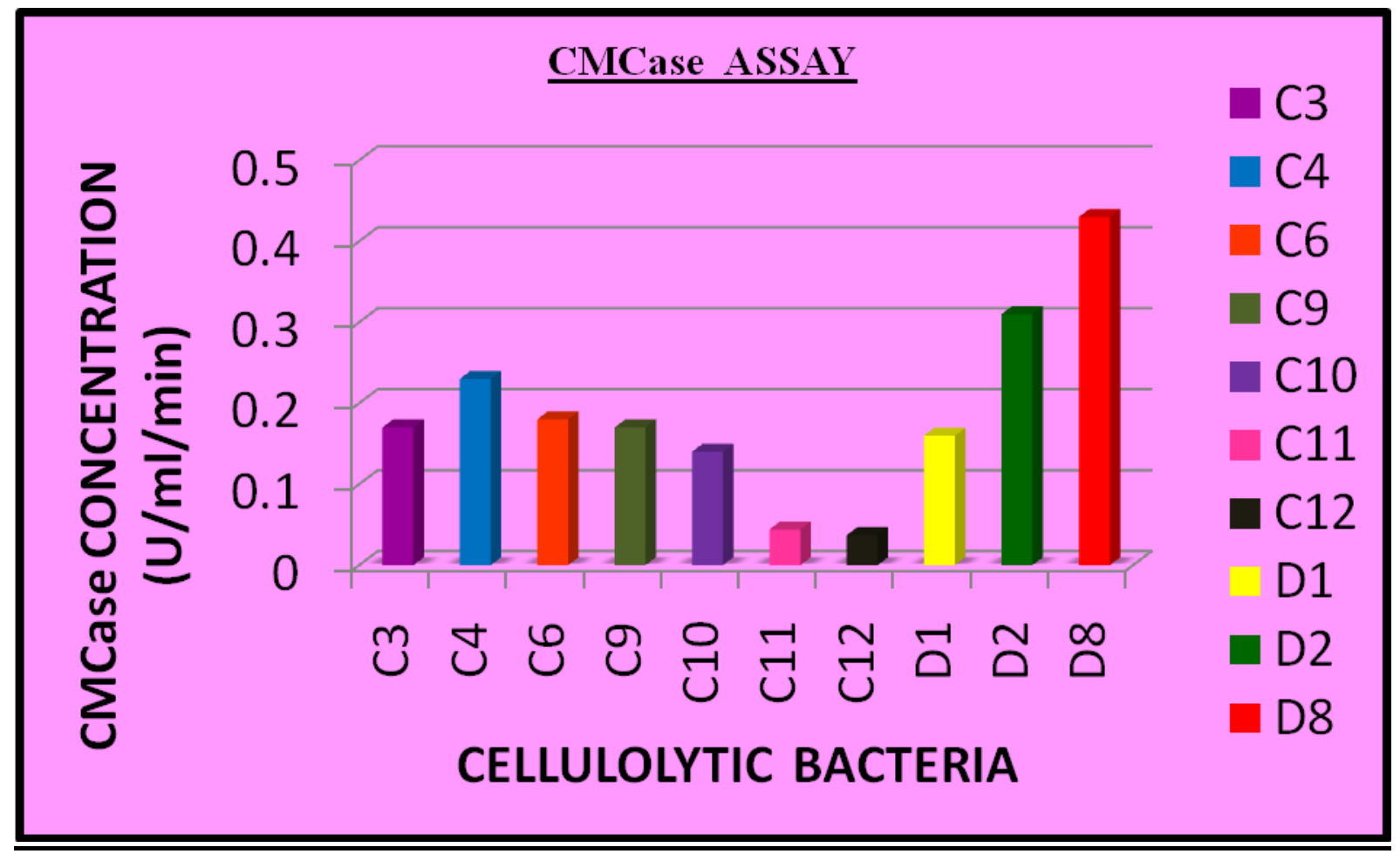


Chart.3 Results of Inductively coupled Plasma Mass spectroscopy Analysis

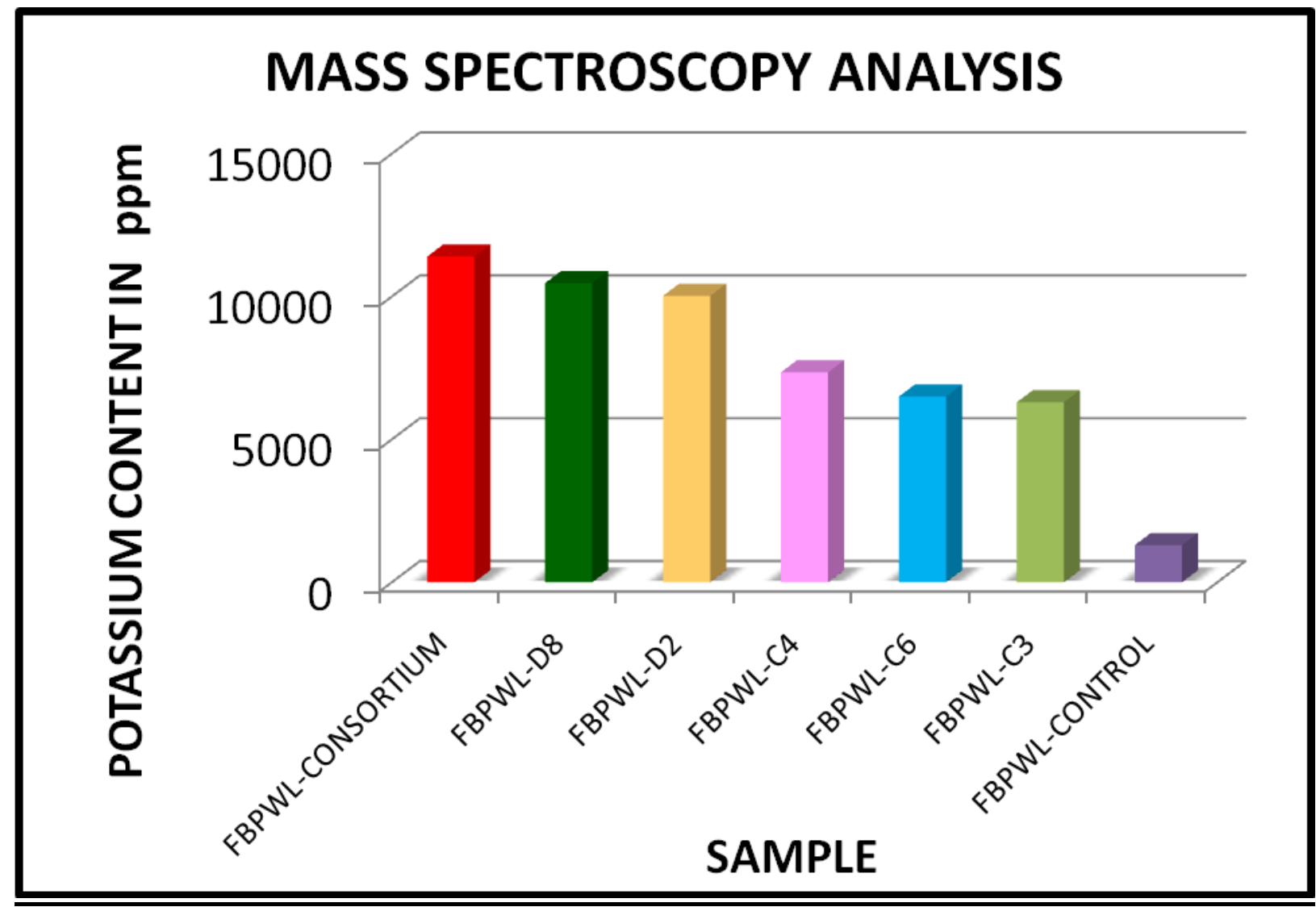

Chart.4 Results of plant growth analysis

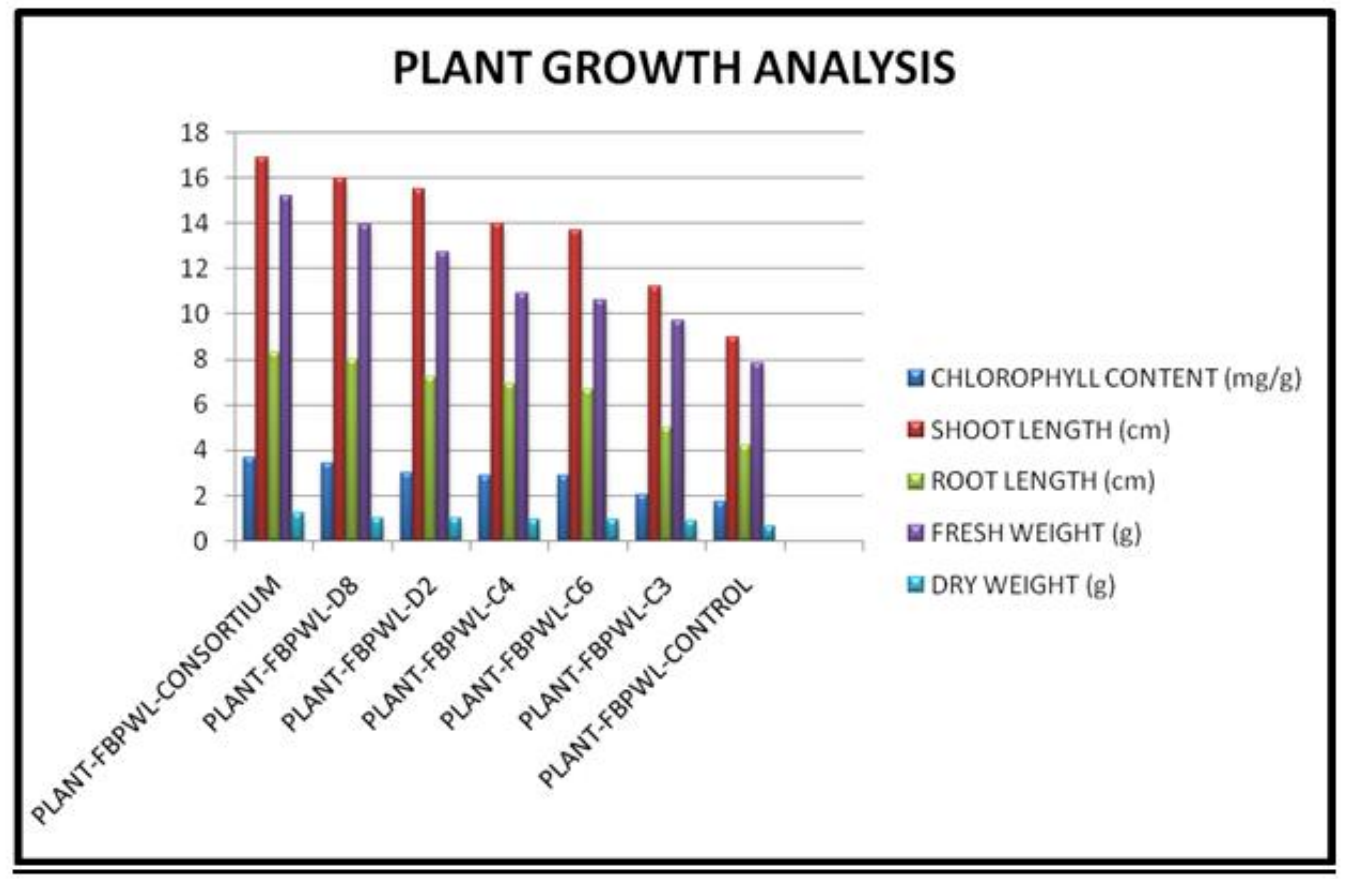


Figure.1 Colony Morphology of Isolates

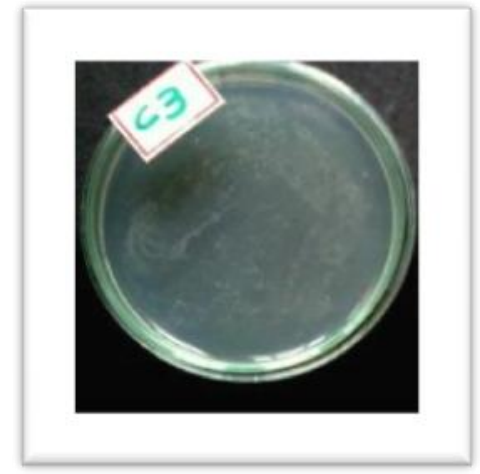

Bacillus circulans

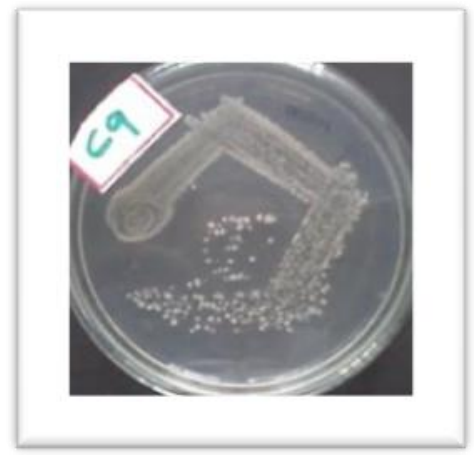

Bacillus simplex

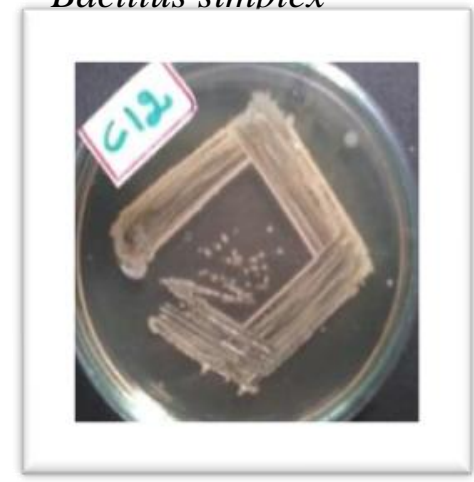

Bacillus megaterium
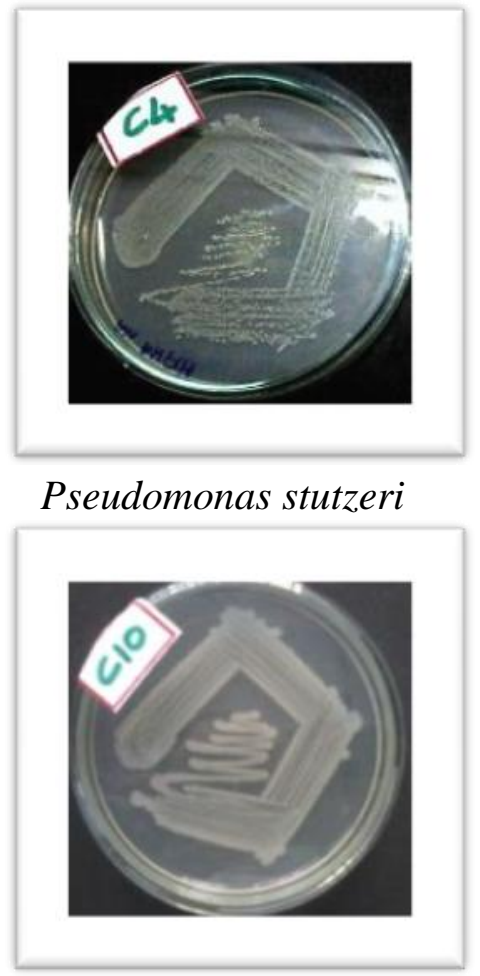

Bacillus coagulans

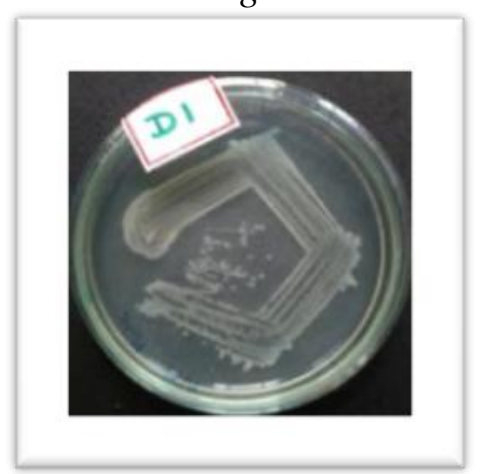

Bacillus subtilis

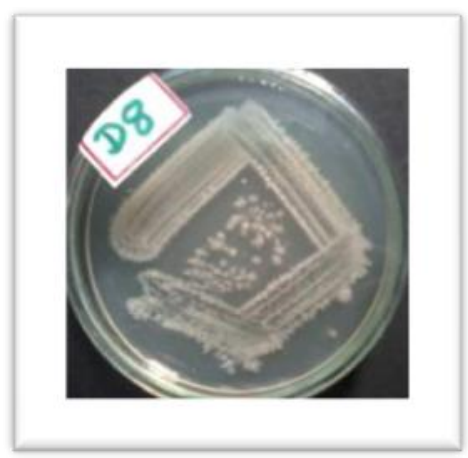

Bacillus aerius

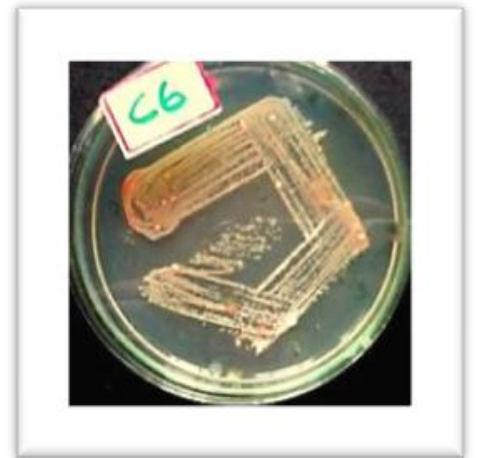

Serratia rubidaea

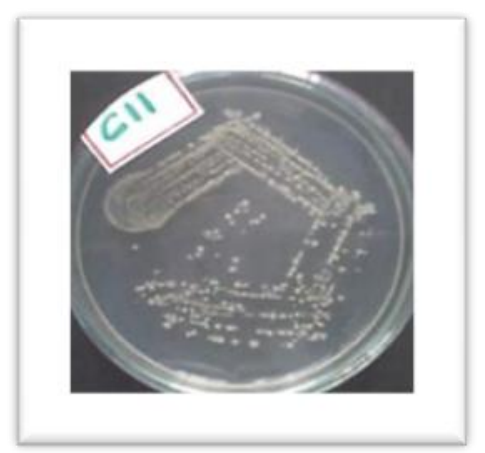

Pseudomonas fragi

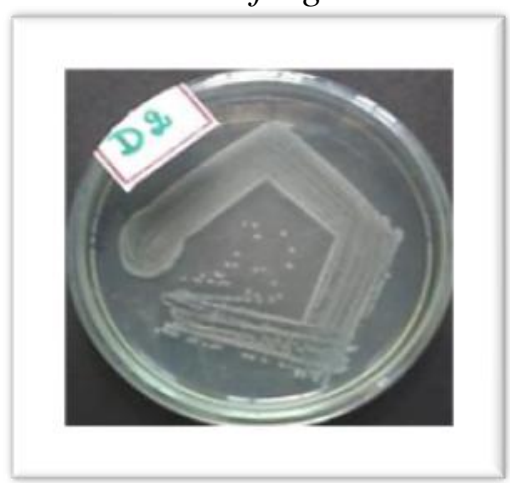

Bacillus pumilus 
Fig.2 Zones formed by D8, D2 and C4 on Congo red assay

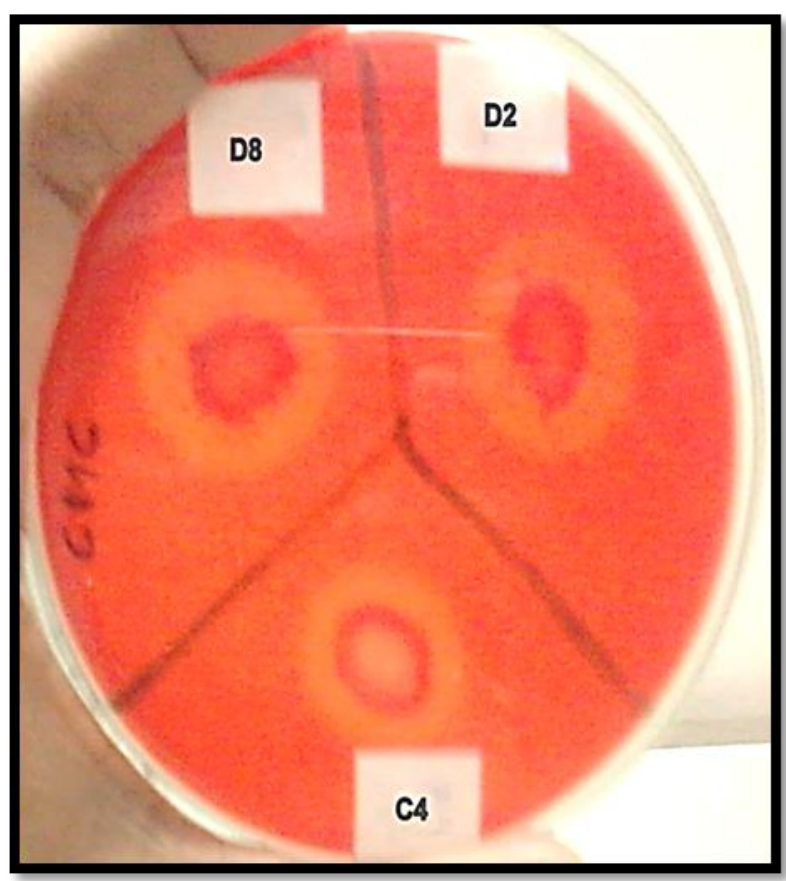

Fig.3 Root length and Shoot length of plants

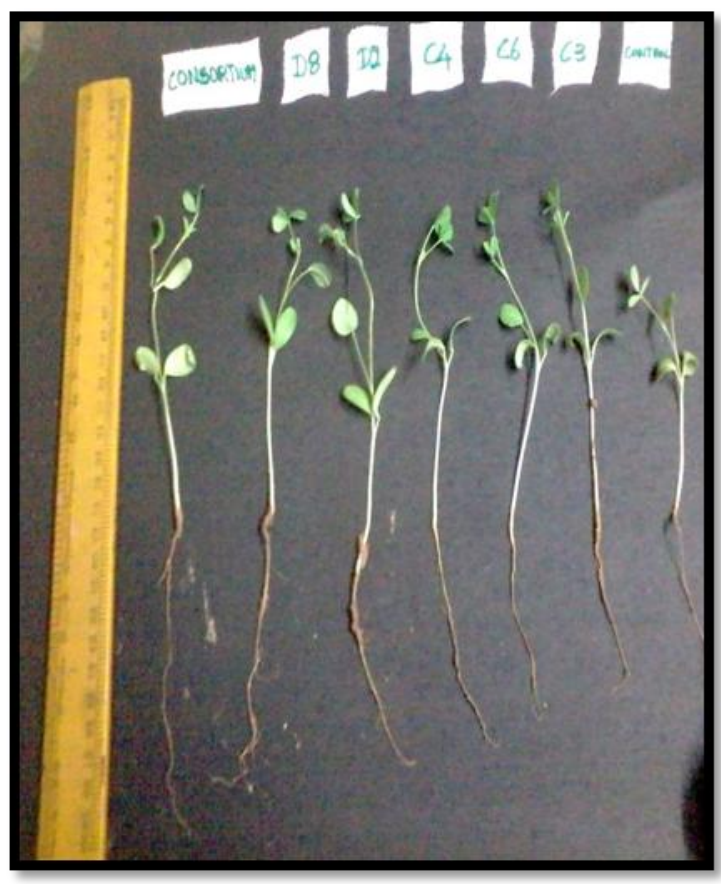


Fig.4 Phylogenetic tree of Bacillus aerius D8

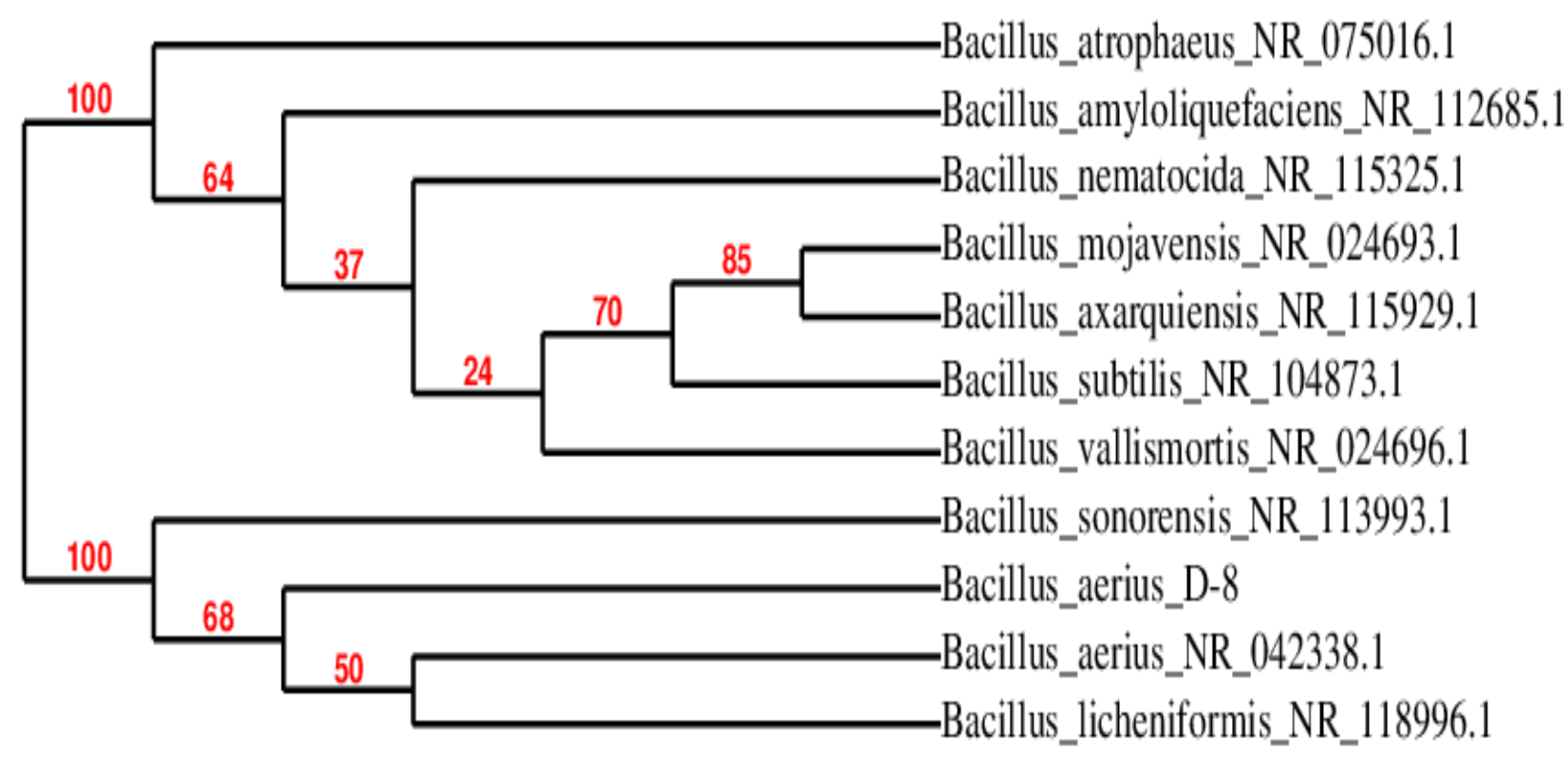

The present study shows that potassic biofertilizer can be produced from banana pseudostem waste and it was found to be effective in enhancing plant growth.

In conclusion, attempts to produce indigenous potassium fertilizer in India are being intensively made and research has been carried out at national and state level. Different approaches were followed to produce potassic fertilizers. But the use of an abundant potassium rich banana pseudostem waste for the production of potassic biofertilizer is an unexplored area and hence formed the basis of the study.

The present study proves that banana pseudostem waste can be used to produce potassic biofertilizer using cellulolytic bacteria as it degrades the cellulose present in banana pseudostem waste and releases the bound potassium. The methodology adopted is simple and cost effective. It also helps in turning a waste to wealth. Banana pseudostem waste which is abandoned in the field can be routed back to support agriculture. Thus, the present study revealed the possibility of utilising banana pseudostem waste as a substrate for the production of potassic biofertilizer.

\section{References}

Dabhi, B.K., Vyas, R.V. and Shelat, H.N. 2014. Use of Banana Waste for the Production of Cellulolytic Enzymes under Solid Substrate Fermentation Using Bacterial Consortium. Int. J. Curr. Microbiol. App. Sci., 3(1): 337346.

Dereeper, A., Guignon, V., Blanc, G., Audic, S., Buffet, S., Chevenet, F., Dufayard, J.F., Guindon, S., Lefort, V., Lescot, M., Claverie, J.M., Gascuel, O. 2008. Phylogeny.fr: robust phylogenetic analysis for thenon-specialist. Nucleic Acids Res., $1: 36$.

Edgar, R.C. 2004. MUSCLE: multiple sequence alignment with high accuracy and high throughput. Nucleic Acids Res., 32(5): 1792-1797. 
Kapoor, N. and Pande, V. 2015. Effect of Salt Stress on Growth Parameters, Moisture Content, Relative Water Content and Photosynthetic Pigments of Fenugreek Variety RMt-1. J. Plant Sci., 10(6): 210-221.

Kaur, M. and Arora, S. 2012. Isolation and Screening of Cellulose Degrading Bacteria in Kitchen Waste and Detecting Their Degrading Potential. IOSR Journal of Mechanical and Civil Engineering (IOSRJMCE)., Volume 1, Issue $2: 33-35$.

Khan, J.A., Ranjan, R.K., Rathod, V. and Gautam, P. 2011. Deciphering Cow Dung for Cellulase Producing Bacteria. European J. Experimental Biol., 1(1): 139-147.

Kinekar, B.K. 2011. Potassium fertilizer situation in India : Current use and perspectives. Karnataka J. Agric. Sci., 24(1): 1-6.

Li, K., Fu, S., Zhan, S. and Lucia, L.A. 2010. Analysis of the chemical composition and morphological structure of Banana Pseudo stem. Biores., 5(2): 576-586.
Lim, S.F. and Matu, S.U. 2015. Utilization of agro-wastes to produce bio fertilizer. Int J Energy Environ Eng., 6: 31-35.

Saibaba, K.V.N., Sarvamangala, D., Kandisa, R.V., Gopinadh, R. and King, P. 2013. Response Surface Optimization of Potassium Extraction from Waste Banana Pseudo-Stem. J. Fundam. Renewable Energy Appl., 4: $1-5$.

Shivaji, S., Chaturvedi, P., Suresh, K., Reddy, G.S.N., Dutt, C.B.S., Wainwright, M., Narlikar, J.V., and Bhargava, P.M. 2006. Bacillus aerius sp. nov., Bacillus aerophilus sp. nov., Bacillus stratosphericus sp. nov. and Bacillus altitudinis sp. nov., isolated from cryogenic tubes used for collecting air samples from high altitudes. Int. J. Systematic and Evol. Microbiol., 56: 1465-1473.

Talavera, G., Castresana, J. 2007. Improvement of phylogenies after removing divergent andambiguously aligned blocks from protein sequence alignments. Systematic Biol., 56: 564577.

\section{How to cite this article:}

Mahalakshmi, R., and Linnett Naveena, M. 2016. Usage of Banana Pseudostem Waste for the Production of Potassic Biofertilizer using Cellulolytic Bacteria. Int.J.Curr.Microbiol.App.Sci. 5(8): 336-349. doi: http://dx.doi.org/10.20546/ijcmas.2016.508.036 